\title{
“DESEMPENHO ZOOTÉCNICO DE ALEVINOS DE TILÁPIAS DO NILO (Oreochromis niloticus) ALIMENTADOS COM LEVEDURA DE Saccharomyces cerevisiae
}

\author{
K. K. SCHWARZ ${ }^{1 *}$, J. C. DO NASCIMENTO², V. A. A. GOMES², C. H. DA SILVA², J. G. SALVADOR ${ }^{2}$, \\ M. R. FERNANDES ${ }^{2}$ e R. M. NUNES ${ }^{2}$;
}

'Laboratório Multidisciplinar de Estudos em Animais - Universidade Estadual do Paraná, Campus FAFIPAR;

${ }^{2}$ Alunos/bolsistas - Universidade Estadual do Paraná, Campus FAFIPAR.

Kátia.kalko@fafipar.br*

Artigo submetido em dezembro/2013 e aceito em abril/2016

DOI: 10.15628/holos.2016.1869

\section{RESUMO}

Foi avaliado os efeitos da adição de Levedura Saccharomyces cerevisiae (Biosaf $\mathrm{HR}^{\circledR}, 8$ bilhões UFC) em ração peletizada $(\mathrm{PB}=35 \%$; $\mathrm{ED}=3.333 .00 \mathrm{Kcal} / \mathrm{kg}$. $\mathrm{FB}=$ 3.7; $\mathrm{EE}=6.4 \%$ ) para Tilápia do Nilo (Oreochromis niloticus), utilizando 540 alevinos revertidos sexualmente por choque térmico oriundo da S3 Piscicultura, Registro/SP-Brasil. Os peixes foram distribuídos em 30 tanques de 60 litros cada, em um delineamento inteiramente casualizado. Foram avaliados cinco tratamentos e seis repetições com diferentes níveis de levedura T1:0.00\%. T2:0.10\%. T3:0.20\%. T4:0.30\% e T5:0.40\%. De acordo com os resultados obtidos neste experimento não foram observadas diferenças no desempenho para os 15 dias. Porém pelo teste de Tukey $(p<0,05)$ houve diferenças para a conversão alimentar e ganho em peso aos 30 dias para a dieta com $0.1 \%$ de $\mathrm{S}$. cerevisiae. Aos 60 dias houve diferença $(p<0,05)$ para conversão alimentar e comprimento de intestino para o tratamento que recebeu a dosagem de $0.2 \%$ de levedura S. cerevisiae. Também a dosagem de $0,2 \%$ da levedura foi significativa $(P<0,01)$ para proteína bruta da carcaça de alevinos de tilápia do Nilo. Conclui-se que $0,2 \%$ da levedura adicionada foi eficiente para os alevinos de tilápias.

PALAVRAS-CHAVE: Dieta, peixe, performance, probiótico.

\section{ZOOTECHNICAL PERFORMANCE NILE TILAPIA FINGERLINGS (Oreochromis niloticus) FED OF YEAST Saccharomyces cerevisiae}

\begin{abstract}
Was evaluated the effects of adding yeast Saccharomyces cerevisiae (Biosaf $\mathrm{HR}{ }^{\circledR}$, UFC 8 billion) in pelleted diet (CP $=35 \%, \mathrm{ED}=3.333 .00 \mathrm{Kcal} / \mathrm{kg} . \mathrm{FB}=3.7 ; \mathrm{EE}=6.4 \%$ ) for Nile tilapia (Oreochromis niloticus), using 540 sexually inverted thermal shock arising from S3 Pisciculture, registration/SP-Brazil, distributed in 30 tanks 60 liters each in a completely randomized design. We evaluated five treatments and six repetitions with different levels of yeast T1: $0.00 \%$. T2: $0.10 \%$. T3: $0.20 \%$. T4:0,30\% and $\mathrm{T} 5: 0.40 \%$. According to the results obtained in this experiment was not observed differences in performance
\end{abstract}

for the 15-day trial. But by the Tukey test $(P<0.01)$ differences were found for feed conversion and weight gain at 30 days for diets with $0.1 \%$ of Saccharomyces cerevisiae. And at 60 days was no difference $(P<0.01)$ feed conversion and length of intestine for the treatment you received the dosage of $0.2 \%$ yeast Saccharomyces cerevisiae. Also the $0,2 \%$ dosage of yeast was significant $(P<0,01)$ for crude protein of the Nile tilapia carcass. It is concluded that $0,2 \%$ of yeast added is efficient of fingerlings tilapia.

KEYWORDS: Diet, fish, performance, probiotic 


\section{INTRODUÇÃO}

O Brasil possui condições extremamente favoráveis para o desenvolvimento de diversas modalidades de produção aquícola (CAMARGO \& POUEY, 2005). O país possui em seu interior uma área de mais de 3.5 milhões de hectares de lâmina d'água em reservatório de usinas hidrelétricas (ANEEL) e propriedades particulares (MPA, 2011).

A criação de tilápias é uma atividade que vem crescendo no Brasil, pois estas possuem grande capacidade de adaptação a diversos tipos de ambiente, resistem a grandes variações de temperatura, resistentes a doenças, possuem facilidade na reprodução em larga escala e suportam baixos níveis de oxigênio, o que facilita seu cultivo, bem como na qualidade dos produtos derivados. Estes são alguns dos fatores que levam ao sucesso que esta espécie apresenta na piscicultura (POPMA \& PHELPS, 1998; HAYASHI et al., 1999; MACINTOSH \& LITTLE, 1995; FURUYA et al., 2005; MEURER, 2005; RODRIGUES, 2007).

Porém, o manejo zootécnico desta espécie de peixe, geralmente, pode causar estresse e consequentemente a diminuição da qualidade da água (YOUSEFIAN \& AMIRI, 2009; KUBITZA, 2009) esse estresse reduz o sistema imunológico o que as tornam mais vulneráveis ás infecções bacterianas.

Diante deste fato, as pesquisas com aditivos na nutrição de tilápias têm sido realizadas com a finalidade de melhorar a resistência imunológica, a qualidade da água e o desempenho zootécnico, para fomentar a produção, seja na fase de reprodução, alevinagem ou crescimento até tamanho comercial. A falta de informações referentes à utilização de aditivos que possam contribuir para melhoria do desempenho e da saúde dos peixes, ainda são objetivos a serem alcançados (SCHWARZ, 2009).

Dentre os aditivos utilizados na nutrição de tilápias, a levedura parece ser um ingrediente fundamental na composição das rações, pois atua como imunoestimulante e pro-nutriente, que é o composto que obtém teores nutricionais intrínsecos, exigido em pequenas concentrações na fabricação da ração (BUTOLO, 2001).

A levedura de $S$. cerevisiae é utilizada na fermentação alcoólica para transformar o açúcar em álcool. É rica em vitaminas, especialmente do complexo B, sua composição química varia dependendo da natureza do substrato cultivado (BERTO, 1997; GHIRALDINI \& ROSSELI, 1997). Em relação aos probióticos seu efeito além do peixe, reflete também no ambiente de cultivo, sua utilização em organismos aquáticos tem pontos positivo em atividades de cultivo, combatendo o surgimento de algumas doenças bacterianas (MEURER, 2005).

De acordo com BACCARIN e PEZZATO (2001), a levedura desidratada de álcool pode ser utilizada em dietas de tilápias do Nilo como fontes hidrossolúveis. Sabe-se também que utilização da levedura íntegra em rações para alevinos da tilápia do Nilo promove a colonização do intestino, apresentando efeitos positivos no cultivo, mas pode não influenciar o desempenho produtivo e a sobrevivência em um sistema de cultivo com desafio sanitário (MEURER, 2005; MEURER et al. (2007).

Atualmente a utilização de levedura íntegra, assim como derivados do seu processamento, tais como levedura autolisada, polissacarídeos da parede celular e nucleotídeos, são 
recomendados para serem utilizados na composição das rações para organismos aquáticos HISANO et al. (2007). HISANO et al. (2008) ainda afirmam que a S. cerevisiae como aditivo se incorpora facilmente durante o processamento da ração. HISANO et al. (2008), concluíram que a levedura íntegra da cana-de-açúcar apresenta alto teor proteico e boa digestibilidade para os nutrientes e aminoácidos e ainda melhora a digestibilidade para matéria seca, proteína, energia e a maior parte dos aminoácidos essenciais e não essenciais

De acordo com estudos realizados por GALLINA et al. (2009) a S. cerevisiae provoca alteração na microbiota das mucosas, trazendo benefícios ao organismo e diminuindo a colonização de parasitas. Em estudos realizados por MEURER et al. (2008) com levedura como probiótico na reversão sexual da tilápia do Nilo comprova que seu uso na ração não prejudica o desempenho nem o processo de reversão sexual, e ainda proporciona a colonização do intestino e alterações na sua microbiota. Contudo, há comprovações que a inclusão da levedura na alimentação dos mesmos, diminui o índice hepatossomático (MEURER, 2009).

SCHWARZ et al. (2010) afirmam ainda que a suplementação com a levedura (S. cerevisiae) e com a parede celular (mananoligassacarideo) ajuda na conversão alimentar, no ganho de peso, consumo da dieta e comprimento de intestino para alevinos de tilápias do Nilo (O. niloticus).

$\mathrm{KOCH}$ et al. (2011) concluíram em seus estudos que a levedura de S. cerevisiae afeta positivamente o desempenho de matrizes e alevinos de tilápia, com exceção ao consumo da dieta, e melhora o índice de sobrevivência de alevinos com a dosagem de $1 \%$.

Poucos estudos com o uso de probióticos e prebióticos na nutrição de peixes, ainda são incipientes de acordo com FURUYA et al. (2012). Para tanto, considerando o aumento dos estudos com probióticos, este experimento teve como finalidade, avaliar o desempenho e a qualidade da carcaça de alevinos de tilápia do Nilo, linhagem Gift, alimentados com a levedura de S. cerevisiae.

\section{MATERIAIS E MÉTODOS}

O experimento foi conduzido no Laboratório de Nutrição de Peixes, na UNESPAR Universidade Estadual do Paraná, campus FAFIPAR - Faculdade Estadual de Filosofia Ciências e Letras de Paranaguá, durante 60 dias. Foram utilizados 540 alevinos de tilápia do Nilo (O. niloticus) machos, revertidos sexualmente por choque térmico, oriundos do Laboratório de larvicultura S3 Piscicultura do município de Registro-SP-Brasil.

O peso médio inicial dos alevinos foi de aproximadamente $4,68 \mathrm{~g}$, os quais foram distribuídos aleatoriamente em 30 tanques circulares de polietileno de alta densidade (PEAD) com capacidade de 100 litros contendo a medida de 60 litros de água cada, em uma densidade de estocagem de 18 peixes por tanque por repetição.

Foram oferecidas dietas peletizadas (Tabela 1) em um delineamento inteiramente casualizado, com cinco tratamentos e seis repetições, sendo testado um tratamento testemunha (TT) 0,0\% e quatro com adição da Levedura S. cerevisiae como probiótico (TP), nas concentrações de: T2:0.10\%, T3:0.20\%, T4:0.30\% e T5:0.40\%. 
Tabela 1- Composição Percentual Dos Ingredientes Da Dieta Controle.

\begin{tabular}{|c|c|}
\hline Ingrediente & $(\%)$ \\
\hline Farelo de soja & 40,00 \\
\hline Farinha de peixe & 25,00 \\
\hline Farelo de trigo & 12,00 \\
\hline Milho Moído & 11,21 \\
\hline Quirera de Arroz & 5,00 \\
\hline Óleo de soja & 3,00 \\
\hline Fosfato bicálcico & 2,00 \\
\hline Sal Comum & 0,50 \\
\hline Suplemento mineral vitamínico ${ }^{1}$ & 0,60 \\
\hline L-lisina & 0,20 \\
\hline DL-metionina & 0,20 \\
\hline Vitamina C & 0,15 \\
\hline $\mathrm{BHT}$ & 0,04 \\
\hline Antifúngico & 0,10 \\
\hline TOTAL & 100,00 \\
\hline Proteína bruta $(\%)^{2}$ & 35,00 \\
\hline Energia digestível $(\mathrm{kcal} / \mathrm{kg})^{2}$ & 3333,00 \\
\hline Fibra bruta $(\%)^{2}$ & 3,70 \\
\hline Cálcio $(\%)^{2}$ & 1,86 \\
\hline Fósforo disponível (\%) ${ }^{1}$ & 0,90 \\
\hline Extrato etéreo $(\%)^{2}$ & 6,40 \\
\hline Vitamina $\mathrm{C},(\mathrm{mg} / \mathrm{kg})^{1}$ & 640,00 \\
\hline
\end{tabular}

${ }^{1}$ Suplemento Mineral Vitamínico: Composição por kg: Vit. $A=1200.000 U$ I; vit. $D 3=200.000 U$ I; vit. $E=12.000$ $\mathrm{mg}$; vit. $\mathrm{K} 3=2.400 \mathrm{mg}$; vit. $\mathrm{B} 1=4.800 \mathrm{mg}$; vit. $\mathrm{B} 2=4.800 \mathrm{mg}$; vit. $\mathrm{B} 6=4.000 \mathrm{mg}$; vit. $\mathrm{B} 12=4.800 \mathrm{mg}$; ácidofólico $=1.200$ $\mathrm{mg}$; pantotenato de $\mathrm{Ca}=12.000 \mathrm{mg}$; vitamina $\mathrm{C}=48.000 \mathrm{mg}$; biotina $=48 \mathrm{mg}$; colina $=65.000 \mathrm{mg}$; niacina $=24.000 \mathrm{mg}$; $\mathrm{Cu}=600 \mathrm{mg} ; \mathrm{Fe}=10.000 \mathrm{mg} ; \mathrm{Cu}=600 \mathrm{mg} ; \mathrm{Mg}=4.000 \mathrm{mg} ; \mathrm{Zn}=6.000 \mathrm{mg} ; \mathrm{I}=20 \mathrm{mg} ; \mathrm{Co}=2 \mathrm{mg}$ e Se=20 mg. A adição de MOS foi realizada por meio da substituição do milho.

$\mathrm{Na}$ elaboração da ração foi acrescentado água a temperatura de 60 ㄷ para homogeneização dos ingredientes que foram moídos e peneirados a $500 \mu \mathrm{m}$, em uma proporção de $30 \%$ sobre o peso seco da dieta. Após a homogenização a massa preparada foi peletizada e desidratada em estufa de ventilação forçada à temperatura de $50^{\circ} \mathrm{C}$, durante o período de três horas, em seguida foi levada para a estufa de ventilação à temperatura ambiente, para eliminação do excesso de umidade.

A ração foi distribuída três vezes ao dia, às 8 horas, 13 horas e 18 horas, por arraçoamento manual ad libtum. A limpeza dos tanques foi realizada uma vez ao dia no período da tarde (16 horas), através do método da sifonagem, para a retirada das fezes e eventuais restos de rações, removendo-se cerca de $50 \%$ da água durante todos os dias do experimento. A temperatura e o oxigênio dissolvido da água foram aferidos diariamente, durante a manhã (8 horas) e no final da tarde (18 horas) com oxímetro digital. Os demais parâmetros, pH, amônia, nitrito e nitrato foram mensurados semanalmente com o auxílio de "kits" Labcontest ${ }^{\circledR}$ e Papel Indicador Universal Merk ${ }^{\bullet}$.

Os peixes foram pesados e medidos com balança de precisão e paquímetro, respectivamente. No primeiro dia do experimento individualmente, aos 15 e 30 dias foram pesados em blocos e aos 60 dias (ultimo dia do experimento), individualmente.

Ao final do experimento os peixes foram pesados, medidos, contados individualmente para determinação dos parâmetros de ganho de peso (GP = peso final - peso inicial), conversão 
alimentar (CA = consumo de ração/ganho de peso) e taxa de crescimento [TCE $=\operatorname{Ln}($ peso total $)-\operatorname{Ln}$ (peso total inicial) / dias de experimento].

A composição química da carcaça foi obtida utilizando-se oito peixes de cada unidade experimental. As análises químicas das carcaças foram analisadas no Lab Tec (Laboratório de Análises Químicas Ltda) seguindo a metodologia citada por SILVA \& QUEIROZ (2002).

Todos os dados obtidos foram analisados estatisticamente, por análise de variância (ANOVA), pelo programa estatístico ASSISTAT ${ }^{\circledR}$, e teste de Tukey $(p<0,05)$ de significância.

\section{RESULTADOS E DISCUSSÕES}

A média dos parâmetros físicos (oxigênio, temperatura e $\mathrm{pH}$ ) e químicos (amônia) foram respectivamente, $22.16 \pm 1.20^{\circ} \mathrm{C}, 13.28 \pm 3.33 \mathrm{mg} \mathrm{L}-1,6.42 \pm 0.53$ e $0.0104 \pm 0.0058 \mathrm{mg} \mathrm{L}-1$. A temperatura não diferiu entre os tanques durante o experimento, porém de acordo com SILVA (2009) a temperatura foi considerada baixa para a sobrevivência da espécie, podendo ter interferindo nos resultados obtidos neste estudo. Os níveis de oxigênio dissolvido mantiveram-se acima de $5.0 \mathrm{mg} \mathrm{L-1,} \mathrm{o} \mathrm{valor} \mathrm{do} \mathrm{pH,} \mathrm{amônia,} \mathrm{nitrito} \mathrm{e} \mathrm{nitrato} \mathrm{estiveram} \mathrm{de} \mathrm{acordo} \mathrm{com} \mathrm{a} \mathrm{faixa} \mathrm{de}$ conforto para esta espécie de alevinos de peixe.

As variações dos aspectos químicos da água obtidos durante o experimento podem estar relacionados ao baixo volume de água, aos dejetos eliminados pelos peixes e resíduos que se acumulam ao fundo.

Os resultados de biomassa inicial, consumo alimentar, conversão alimentar, peso aos 15 dias e sobrevivência dos alevinos das unidades experimentais não diferiram entre os tratamentos $(p>0,05)$, não havendo diferenças significativas, no período de 0 a 15 dias. Os níveis de levedura a ração (Tabela 1) não influenciaram o consumo alimentar durante a primeira quinzena (Tabela 2).

Tabela 2. Desempenho De Alevinos De Tilápia Do Nilo Alimentados Com Dietas Contendo Níveis Crescentes De S. Cerevisiae, No Período De 0-15 Dias.

\begin{tabular}{c|c|c|c|c|c|c}
\hline \multirow{2}{*}{ Variável } & \multicolumn{5}{c}{ Levedura S. cerevisiae } & \\
\cline { 2 - 7 } & T1 & T2 & T3 & T4 & T5 & $\mathrm{CV}^{1}$ \\
\hline Peso Inicial (g) & 4.68 & 4.68 & 4.68 & 4.68 & 4.68 & 2.97 \\
\hline Ganho em Peso (g) & 3.15 & 2.96 & 3.16 & 2.97 & 2.91 & 14.48 \\
\hline Consumo Alimentar (g) & 81.32 & 78.71 & 78.92 & 80.28 & 78.66 & 4.59 \\
\hline Conversão Alimentar & 1.53 & 1.54 & 1.44 & 1.53 & 1.53 & 14.7 \\
\hline Peso aos 15 dias (g) & 8.14 & 7.58 & 7.94 & 7.62 & 7.41 & 5.34 \\
\hline Peixes vivos & 17.416 & 17.83 & 17.5 & 17.83 & 17.66 & 3.07 \\
\hline \multicolumn{7}{c}{${ }^{1}$ Coeficiente de Variação } \\
\hline
\end{tabular}

Onde: $\mathrm{T} 1=0,0 \% ; \mathrm{T} 2=0,1 \% ; \mathrm{T} 3=0,2 \% ; \mathrm{T} 4=0,3 \% ; \mathrm{T} 5=0,4 \%$ levedura de $\mathrm{S}$. cerevisiae.

Os dados de desempenho e sobrevivência obtidos neste experimento estão de acordo com os encontrados por MEURER et al. (2009) em seu trabalho onde foram oferecidos tratamentos com adição da levedura $S$. cerevisiae em rações para tilapia do nilo durante a fase de reversão sexual, neste periodo. BACCARIN e PEZZATO (2001) que substituiram a farinha de peixe pela levedura em seu experimento, comprovaram que os tratamentos sem adição da levedura apresentaram melhor conversão alimentar e também uma melhor taxa de eficiencia protéica. 
Podendo assim, subentender que a substituição total da farinha de peixe, diminui a eficiencia da levedura no desenvolvimento dos peixes.

Os resultados de conversão alimentar e ganho de peso obtidos aos 30 dias descritos na Tabela 3, apresentaram diferenças significativas $(p<0,01)$.

Tabela 3. Desempenho De Alevinos De Tilápia Do Nilo Alimentados Com Dietas Contendo Níveis Crescentes De S. Cerevisiae No Período De 0 A 30 Dias.

\begin{tabular}{|c|c|c|c|c|c|c|}
\hline \multirow{2}{*}{ Variável } & \multicolumn{5}{|c|}{ Levedura (\%)S. cerevisiae } & \multirow[b]{2}{*}{$\mathrm{CV}_{-}^{1}$} \\
\hline & $\mathrm{T} 1$ & $\mathrm{~T} 2$ & T3 & $\mathrm{T4}$ & T5 & \\
\hline Peso Inicial (g) & 4.68 & 4.68 & 4.68 & 4.68 & 4.68 & 2.97 \\
\hline Ganho em Peso (g) & 6.04 & 5.95 & 6.02 & 6.08 & 5.45 & 7.95 \\
\hline Consumo Alimentar (g) & 167.43 & 156.67 & 157.23 & 159.07 & 156.71 & 4.66 \\
\hline Conversão Alimentar ${ }^{2}$ & $1.66^{\mathrm{a}}$ & $1.48^{b}$ & $1.49^{\mathrm{ab}}$ & $1.47^{b}$ & $1.64^{\mathrm{ab}}$ & 7.02 \\
\hline Peso aos 30 dias $(\mathrm{g})^{2}$ & $10.95^{\mathrm{a}}$ & $10.00^{\mathrm{ab}}$ & $1.80^{\mathrm{a}}$ & $10.65^{\mathrm{ab}}$ & $9.84^{b}$ & 5.46 \\
\hline Alevinos Vivos & 16.66 & 17.83 & 17.5 & 17.83 & 17.5 & 3.96 \\
\hline
\end{tabular}

${ }^{1}$ Coeficiente de Variação. ${ }^{2}$ Letras diferentes na mesma linha, indicam diferenças pelo teste de Tukey $(p>0,01)$ entre as médias dos tratamentos. $\mathrm{T} 1=0,0 \% ; \mathrm{T} 2=0,1 \% ; \mathrm{T} 3=0,2 \% ; \mathrm{T} 4=0,3 \% ; \mathrm{T} 5=0,4 \%$ levedura de $\mathrm{S}$. cerevisiae.

Os dados obtidos nesta fase, corroboram com os de LARA-FLORES et al. (2003). HISANO et al. (2007) mostram em seus estudos que a suplementação com levedura e derivados melhora o desempenho produtivo das tilápias, e ainda destaca que não há alteração na composição do filé. Neste mesmo estudo ele constata que a levedura autolisada quando utilizada entre 1.30 e $1.59 \%$ proporciona um maior desempenho.

Porém, MEURER et al. (2007) demonstraram que a colonização do intestino foi promovida pela utilização da levedura S. cerevisiae, porém não houve influência no desempenho produtivo e na sobrevivência em um sistema de cultivo com desafio sanitário.

A utilização da levedura íntegra resultou em uma menor conversão alimentar e de ganho de peso aos 60 dias (Tabela 4) mostrando diferenças significativas. Já os dados de BACCARIN e PEZZATO (2001) contrariam nossos resultados mostrando que o tratamento com levedura obteve uma maior conversão alimentar. Segundo HEPHER (1988) alimentos de baixo valor nutricional melhoram o consumo alimentar, porém há um menor aproveitamento do alimento. SCHWARZ et al. (2010) destacam que o uso da levedura S. cerevisiae melhora a conversão alimentar $(p<0,01)$ para a dosagem de $0,2 \%$, estando de acordo com o presente estudo.

Tabela 4. Desempenho De Alevinos De Tilápia Do Nilo Alimentados Com Dietas Contendo Níveis Crescentes De Saccharomyces Cerevisiae No Período De 0 A 60 Dias.

\begin{tabular}{|c|c|c|c|c|c|c|}
\hline \multirow{2}{*}{$\underline{\text { Variável }}$} & \multicolumn{5}{|c|}{ Levedura (\%) } & \multirow[b]{2}{*}{$\underline{\mathrm{CV}^{1}}$} \\
\hline & $\mathrm{T} 1$ & $\mathrm{~T} 2$ & T3 & T4 & T5 & \\
\hline Peso Inicial (g) & 4.68 & 4.68 & 4.68 & 4.68 & 4.68 & 2.97 \\
\hline Ganho em Peso (g) & 9.56 & 9.76 & 10.1 & 9.63 & 8.99 & 7.04 \\
\hline Consumo Alimentar (g) & 573.06 & 478.69 & 474.66 & 478.93 & 457.92 & 19.26 \\
\hline Conversão Alimentar ${ }^{2}$ & $1.78^{\mathrm{a}}$ & $1.61^{a b}$ & $1.56^{b}$ & $1.63^{a b}$ & $1.71^{\mathrm{ab}}$ & 6.73 \\
\hline Peso aos 60 dias $(\mathrm{g})^{2}$ & $14.28^{a b}$ & $14.40^{\mathrm{ab}}$ & $14.87^{a}$ & $14.25^{\mathrm{ab}}$ & $13.83^{b}$ & 4.59 \\
\hline Alevinos Vivos & 17.00 & 17.66 & 17.5 & 17.83 & 16.66 & 4.76 \\
\hline
\end{tabular}


O tratamento com adição de $0.2 \%$ de levedura S. cerevisae apresentou melhor desempenho zootécnico para os alevinos de tilápia do Nilo. De acordo com LARA-FLORES et al. (2003), a utilização da levedura $S$. cerevisae na formulação das rações obtiveram resultados satisfatório sobre o desempenho e a sobrevivência peixes.

Por outro lado, diferem de MEDRI et al. (1999), cujo trabalho consta um baixo índice de crescimento em comprimento e peso, cujo podem estar relacionados a delimitação fora das normas de densidade populacional, e a uma diminuição da ingestão de alimentos, coincidindo com o período de inverno, diferido com o período e os resultados obtidos neste experimento. Porém, corroboram com os obtidos por MEURER (2000), onde obtiveram um aumento linear $(P<0,05)$ para o peso, comprimento e taxa de eficiência protéicas médios, e na conversão alimentar, com uma melhora linear em relação ao aumento do nível de levedura, mesmo que não haja diferença estatística no consumo alimentar, coincidem positivamente com os dados obtidos neste trabalho, conjuntamente com dados encontrados por BACCARIN et al. (2001) devido ao bom desempenho de conversão alimentar e ganho de peso/taxa de crescimento, que são semelhantes com estes resultados obtidos.

Para o desempenho de proteína bruta, extrato etéreo, umidade, matéria mineral, cálcio e fósforo da carcaça dos alevinos de tilápia, estão descritos na tabela 5.

Os dados de proteína bruta na carcaça foram significativos $(P>0,01)$ para o tratamento com $0,2 \%$ de levedura na dieta. Com relação aos níveis de cálcio, a carcaça com dieta contendo $0,4 \%$ de S.Cerevisiae apresentou maior deposição deste mineral, quando comparado ao tratamento testemunha, porém para fósforo os resultados não foram significativos.

HISANO et al. (2007) constataram que as dietas com uso de levedura em rações para alevinos de tilápia melhoram a qualidade produtiva, sem alterações no que diz respeito a carcaça, e na avaliação de dieta, a levedura autolisada causa maior suporte quando utilizada entre 1,30 e 1,59\%. Com relação do estudo de HISANO et al. (2007) e estes resultados obtidos dos tratamentos T1 e T2 não exibem significância de alteração na carcaça dos alevinos.

Tabela 5 - Desempenho de carcaça de alevinos de tilápia do nilo alimentados com dietas específicas por tratamentos ( $\mathrm{T} 1=0,0 \% ; \mathrm{T} 2=0,1 \% ; \mathrm{T} 3=0,2 \% ; \mathrm{T} 4=0,3 \% ; \mathrm{T} 5=0,4 \%$ ) contendo níveis crescentes de s.cerevisiae no período de 60 dias.

\begin{tabular}{c|c|c|c|c|c|c}
\hline PARÂMETROS & T1 & T2 & T3 & T4 & T5 & CV\% $^{1}$ \\
\hline Proteína Bruta $^{2}$ & $64,95^{\mathrm{b}}$ & $64,2^{\mathrm{c}}$ & $65,54^{\mathrm{a}}$ & $64,33^{\mathrm{c}}$ & $64,56^{\mathrm{bc}}$ & 0,28 \\
\hline Estrato Etéreo $^{2}$ & $11,74^{\mathrm{ab}}$ & $12,85^{\mathrm{a}}$ & $11,01^{\mathrm{b}}$ & $12,27^{\mathrm{ab}}$ & $12,16^{\mathrm{ab}}$ & 5,14 \\
\hline Umidade & $2,44^{\mathrm{ab}}$ & $2,46^{\mathrm{a}}$ & $2,42^{\mathrm{ab}}$ & $2,13^{\mathrm{b}}$ & $2,54^{\mathrm{a}}$ & 6,05 \\
\hline Matéria Mineral & $20,37^{\mathrm{a}}$ & $19,01^{\mathrm{b}}$ & $20,41^{\mathrm{a}}$ & $19,74^{\mathrm{ab}}$ & $19,56^{\mathrm{ab}}$ & 2,79 \\
\hline Cálcio & $5,61^{\mathrm{b}}$ & $5,82^{\mathrm{ab}}$ & $5,8^{\mathrm{ab}}$ & $5,69^{\mathrm{ab}}$ & $5,62^{\mathrm{a}}$ & 2,05 \\
\hline Fósforo & $3,15^{\mathrm{a}}$ & $3,25^{\mathrm{a}}$ & $3,17^{\mathrm{a}}$ & $3,18^{\mathrm{a}}$ & $3,32^{\mathrm{a}}$ & 3,19 \\
\hline \multicolumn{7}{c|}{${ }^{1}$ Coeficiente de Variação }
\end{tabular}

${ }^{2}$ Letras diferentes na mesma linha indicam diferenças pelo teste de Tukey $(P>0.01)$ entre as médias dos tratamentos.

Em estudos realizados por $\mathrm{KOCH}$ et al. (2011) com relação aos resultados de carcaça, apenas estão de acordo os resultados para matéria mineral. Por outro lado nos resultados descritos na tabela 5, é observado que com exceção ao fósforo, todos os demais tratamentos foram significativos $(P<0,05)$, principalmente para a proteína. 
Estes resultados diferem, por a formulação da dieta nutricional diferenciar nos nutrientes e nas exigências de proteína e calorias. Também a dosagem de $2 \%$ da levedura em relação ao deste estudo que foi de $0,2 \%$, apresentando resultados, devido provavelmente ao alto índice de unidades formadoras de colônia, que esta levedura apresentou, não necessitando para isso de altas dosagens.

Outros aspectos que diferenciaram deste estudo, são os condicionamentos ambientais de MEDRI et al. (1999) que diferem com as obtidas neste experimento, assim como as unidades formadoras de colônia, não especificado por KOCH et al. (2011).

\section{CONCLUSÃO}

Não houve diferenças significativa no período entre 0 e 15 dias de experimentação no desempenho dos alevinos. Porém no período de 15 à 60 dias houve significância para a conversão alimentar e peso dos alevinos.

A dosagem de 0,20\% de levedura Saccharomyces cerevisiae de acordo com o trabalho é a mais eficiente e economicamente viável, para adicionar em dietas comerciais.

A utilização de $0,2 \%$ da levedura de $S$. cerevisiae na dieta de alevinos de tilápia do Nilo apresentou melhor deposição de proteína bruta na carcaça, bem como melhorou a conversão alimentar e manteve ganho de peso ideal.

\section{REFERÊNCIAS}

1. BACCARIN. A. E.; PEZZATO. L. E. Efeito da levedura desidratada de álcool em dietas para tilápiado-Nilo. Pesquisa Agropecuaria Brasileira. Brasilia. v.36. n.3 p.549-556, 2001.

2. BERTO, D. A. (1997). Uso da levedura desidratada na alimentação de suínos. In: Simpósio sobre tecnologia da produção e utilização da levedura desidratada na alimentação animal.n. 8, p. 725, 1997.

3. CAMARGO. S.G.O; POUEY. J.L.O.F. Aqüicultura - Um mercado em expansão. Revista brasileira de Agrociência. Pelotas. v.11. n.4. p.393-396, 2005.

4. FURUYA, W.M.; BOTARO, D.; MACEDO, R.M.G; SANTOS V. G.; SILVA L. C. R.; SILVA T. C.; FURUYA V. R. B.; SALES P. J. P. Aplicação do conceito de proteína ideal para redução dos níveis de proteína em dietas para tilápia-do-nilo (Oreochromis niloticus). Revista Brasileira de Zootecnia. v. 34, n.5, p. 1433-1441, 2005.

5. FURUYA, W.M.; PEZZATO, L.E.; BARROS, M.M.; CYRINO, J.E.P. Exigências nutricionais e alimentação em tilápia. In: FRACALOSSI, D.M. e CYRINO, J.E.P. Nutrição e alimentação de espécies de interesse para a aqüicultura brasileira- NUTRIAQUA. Florianópolis: Sociedade Brasileira de Aquicultura e Biologia aquática, 2012. Gráfica e Editora Copiart Ltda. p. 255-268, 2012.

6. GALLINA. T.; WENDT. E. W.; DIAS DE CASTRO. L. L. et al. Utilização de probióticos no controle de infecção de Haemonchus contortus em ovinos. In: XVII Centro de Iniciação Científica. Pelotas. 2009.

7. GHIRALDINI, J. A.; ROSSELI, C. E. V. I. Simpósio sobre tecnologia da produção e utilização da 
levedura desidratada na alimentação animal. n. 8, p. 27-49, 1997.

8. HAYASHI C.; BOSCOLO W. R.; SOARES C. M; BOSCOLO V. R.; GALDIOLI E. M. Uso de diferentes graus de moagem dos ingredientes em dietas para a tilápia do Nilo (Oreochromis niloticus L.) na fase de crescimento. Acta Scientiarum, v.21, n.3, p. 733-737, 1999.

9. HEPHER. B. Nutrition of pond fishes. Cambridge. Inglaterra: Cambridge University Press. 406 p, 1988.

10. HISANO, H.; SOLARTE. WVN; BARROS, MN; PEZZATO, L.E. Desempenho produtivo de alevinos de tilápia do Nilo alimentados com leveduras e derivados. Pesquisa Agropecuaria Brasileira. Brasilia, v. 42, n. 7, p. 1035-1042, 2007.

11. HISANO. H.; SAMPAIO. F. G.; BARROS. M. M.; PEZZATO. L. E. Composição nutricional e digestibilidade aparente da levedura íntegra. da levedura autolisada e da parede celular pela tilápia-do-Nilo. Ciência Animal Brasileira. v.9. n.1. p.43-49. 2008.

12. KOCH, J. F.A.; PEZZATO, L. E.; BARROS, M.M et al. Levedura como pronutriente em dietas para matrizes e alevinos de tilápia-do-nilo. Revista Brasileira de Zootecnia. v.40, n.11, p.2281-2289, 2011.

13. KUBITZA, F. 2003 Qualidade de água no cultivo de peixes e camarões, 1a ed, Jundiaí, p 229.

14. LARA-FLORES. M.; OLVEA-NOVOA. M. A.; GUZMAN-MENDEZ. B. E. et al. Use of bactery Streptococcus faecium and Lactobacilus acidophilus. and the yeast Saccharomyces cerevisiae as growth promoters in Nile tilapia (Oreochromis niloticus). Aquaculture. v.216. n.1-4. p.193201, 2003.

15. MACINTOSH, D.J.; LITTLE, D.C. Nile tilapia (Oreochromis niloticus) BROMAGE, N.R.; ROBERTS, R.J. Broodstock management and egg and larval quality, 277-320, 1995.

16. MEDRI V.; PEREIRA. G. V.; LEONHARDT J. H. Crescimento de Tilápia do Nilo Oreochromis niloticus alimentada com diferentes níveis de levedura alcooleira, alocada em tanque rede. Boletim do Instituto de Pesca de São Paulo. São Paulo. n. 25, p. 51 - 59, 1999.

17. MEURER. F. Levedura (Sacchaomyces cerevisiae) como probiótico para as fases iniciais do cultivo da tilápia do Nilo (Oreochromis niloticus). 2005. 85 f. Tese (Doutorado em Zootecnia) - Centro de Ciências Agrárias. Universidade Estadual de Maringá. Maringá. 2005.

18. MEURER. F.; HAYASHI. C.; COSTA. M. M; FRECCIA. A; MAUERWERK. M.T. Saccharomyces cerevisiae como probiótico para alevinos de tilápia do Nilo submetidos a desafio sanitário. Revista Brasileira de Zootecnia. v.36. n.5. p.1219-1224, 2007.

19. MEURER. F.; HAYASHI. C.; COSTA. M. M.; MASCIOLI. A. S.; COLPINI. L. M. S.; FRECCIA. A. Levedura como probiótico na reversão sexual da tilápia-do-Nilo. Revista Brasileira de Saúde e Produção Animal. v.9. n.4. p.804-812. 2008.

20. MEURER. F.; SILVA. M. S.; COSTA. M. M. et al. Probiótico com levedura na alimentação de tilápia do Nilo. durante o período de reversão sexual. cultivada em água de tanque de cultivo. Revista Brasileira de Zootecnia. v.10. n.2. p.406-416. 2009.

21. Ministério de Pesca e Aquicultura. Participação da aquicultura no setor pesqueiro nacional. 2011. Disponível em http://www.mpa.gov.br/aquiculturampa/informacoes/producao> Acesso em 21/05/2012. 
22. POPMA, T. J.; PHELPS, R. P. Status report to commercial tilápia producers on monosex fingerling productions techniques, Aquicultura do Brasil, Recife 10: 127-145, 1998.

23. RODRIGUES. E. Pesquisa de Aeromonas spp. em tilápia (Oreochromis niloticus). cultivada no estado do Rio de Janeiro - Brasil; isolamento. identificação de espécies e avaliação de sensibilidade antimicrobiana. 2007. 208 f. Tese (Doutorado em Medicina Veterinaria) Centro de Ciências Médicas. Universidade Estadual de Fluminense. Niteroi. 2007.

24. SCHWARZ. K.K. Mananoligossacarídeo em Dietas para Larvas e Juvenis de Tilápia do Nilo. 2009. Tese (Doutorado em Zooecnia) Universidade Estadual de Maringá. Centro de Ciências Agrárias. Maringá - PR. 75p, 2009.

25. SCHWARZ. K. K.; FURUYA. W. M.; NATALI. M. R. M.; MICHELATO. M.; GUALDEZI. M. C. Mananoligossacarídeo em dietas para juvenis de tilápia do Nilo. Revista Eletrônica Acta Scientiarum. Animal Sciences. Maringá. v. 32. n. 2. p. 197-203, 2010.

26. YOUSEFIAN M.; AMIRI M. S. A review of the use of prebiotic in aquaculture for fish and shrimp, Africa Journal Biotechnology. n. 8, p. 7313-7318, 2009. 